\title{
Sobre la Docencia en la Cultura Visual: Perspectivas, Prácticas y Competencias Transversales
}

\section{Victoria E. Bonet-Solves}

Profesora Titular de Historia del Arte. Departamento de Composición Arquitectónica-ETSA. vibone@cpa.upv.es

\begin{abstract}
The introduction of the Bologna Process in the School of Architecture at the Universitat Politècnica de València was an opportunity to rethink and propose new subjects related to Art. A decision was made to offer a renewed programme of study for History of Art where the artwork and the cross-disciplinary quality of the themes were the main characters, overcoming, thus, the traditional diachronic view. On the other hand, the elective course focused on visual culture and image, appropriate to an average group of students accustomed to them through the multiple screens faced in their daily lives. In both, the focus is not only set on the learning process, but also on the objective that the student will be able to continue with his academic education once the course is completed. This is achieved through a new way of looking at artistic production and practical activities of a different profile, where other skills add to the general knowledge of the subject. These exercises encourage the students to research and investigate beyond the artistic disciplines learnt in the classroom, providing them with the opportunity to develop skills such as writing, oral expression and where they can even learn about themselves.
\end{abstract}

Keywords: Visual Culture, Art, Methodology, Blogs, Practical Activities, Skills, Writing, Oral Expression.

\begin{abstract}
Resumen
La implantación del Grado en la Escuela Técnica Superior de Arquitectura de la UPV fue una oportunidad para replantear y proponer asignaturas relacionadas con el Arte. Se ofreció un nuevo programa para la Historia del Arte donde la obra y la transversalidad de los temas fueran los protagonistas superando, así, la visión diacrónica tradicional. Por otra parte, la optativa propuesta se centraba en la cultura visual y la imagen, acorde con un alumnado habituado a ellas a través de las múltiples pantallas a las que se enfrenta todos los días. En ambas, el punto de mira está en el aprendizaje, pero también en el objetivo primordial de que el estudiante siga formándose una vez finalizado el curso. Este se consigue con un nuevo modo de ver la producción artística y con unas prácticas de un perfil diferente, donde al conocimiento de la materia se sumen otras destrezas. Se trata de unas prácticas donde se motiva al alumno a indagar más allá de las disciplinas artísticas que se estudian en el aula, donde desarrollen competencias transversales como la escritura, la expresión oral y donde, incluso, aprendan sobre sí mismos.
\end{abstract}

Palabras clave: Cultura Visual, Arte, Metodología, Blogs, Actividades Prácticas, Competencias, Escritura, Expresión Oral. 
Saliendo a relucir aquí, sin saber cómo ni por qué, algunas dolencias sociales, nacidas de la falta de nutrición y del poco uso que se viene haciendo de los benéficos reconstituyentes llamados Aritmética, Lógica, Moral y Sentido Común, convendría dedicar estas páginas... ¿a quién? ¿al infeliz paciente, a los curanderos y droguistas que, llamándose filósofos y políticos, le recetan uno y otro día?... No; las dedico a los que son y deben ser verdaderos médicos: a los maestros de escuela.

Benito Pérez Galdós. Madrid, 1881

\section{Introducción}

En realidad, nada ni nadie te prepara para lo que ha de venir...

Cursos, reuniones, debates, conversaciones sobre el Grado, sobre "Bolonia", sobre el cambio de docencia y la crisis que podía derivarse de su implantación, se multiplicaron durante poco más de un año. Mientras unos te animaban, otros dejaban sonar los tambores de alarma. La documentación, las plantillas, las aplicaciones, las competencias, los plazos, se acumulaban en el ordenador y sobre la mesa para organizar la llegada del nuevo curso. Sin embargo, aunque todo eso sirvió de gran ayuda, no podía librarme de la evidencia: había que afrontar un nuevo modo de docencia y, sobre todo, de aprendizaje. Era una interesante encrucijada para tomar. Por fin, un nuevo camino.

El programa de la asignatura de Historia del Arte en la Escuela Técnica Superior de Arquitectura no había variado sustancialmente desde hacía tiempo. A partir del 2002 se había adaptado al nuevo plan reduciendo de modo drástico el temario, pues se recortó notablemente el número de horas de docencia. Ahora bien, esta circunstancia no había servido para replantear la materia. La adaptación de la asignatura al Grado podía ser una oportunidad para llevar a cabo una revisión de los contenidos. Si algo estaba claro era que:

1. Desde hace un tiempo la materia en el ámbito académico había empezado a superar la tradicional organización diacrónica del Arte, para abordarla desde otras perspectivas transversales y/o interdisciplinares.

2. El estudiante de 2011, que había de empezar la asignatura de Historia del Arte en el Grado no era, en absoluto, el de 1990, año en que comencé mi docencia en la UPV.

3. Había que adaptarse necesariamente a una docencia en la que el aprendizaje se estableciera de un modo distinto o, tal y como yo también quería plantearlo, en el que se formularan y se aprendieran aspectos distintos.

4. Se recortaba una vez más el número de créditos dedicado a la asignatura.

Hasta el curso 2011-12 la Historia del Arte se estudiaba por un estricto orden cronológico y abarcaba desde el Arte Griego al Arte del Siglo XX. Las disciplinas que se estudiaban en ella eran la pintura, la escultura y la arquitectura. La implantación del Grado era la oportunidad idónea para dar forma a una nueva asignatura. Mi punto de partida no fue tanto el deseo de modificar el programa impartido que, por otro lado, era evidente, sino un cambio de perspectiva sobre lo que el alumno de 2011 debía saber sobre el Arte. Los estudiantes de la ETSA nunca han dado con anterioridad la asignatura. Es absolutamente

(c)) BY-NC-ND 2016, Universitat Politècnica de València

Congreso IN-RED (2016) 
incomprensible, pero es una realidad a la que me enfrento año tras año. En la mayoría de los casos, su conocimiento se reduce a los nombres de algunos artistas conocidos y a obras que han descubierto, sobre todo, a través de viajes, películas, publicidad, algún reportaje... La palabra Historia delante de Arte les trae a la memoria una asignatura que, para algunos, ha quedado enterrada por el paso del tiempo. En el planteamiento que les propongo, sin embargo, prefiero poner el acento en la palabra Arte.

Ahora se aborda el estudio de la disciplina con cinco grandes temas que, manteniendo el desarrollo histórico dentro de cada uno de ellos, la explican de un modo transversal y dinámico. Algunos de ellos son, por ejemplo, La construcción de la realidad, El individuo y su representación o El contenido del Arte. Esta nueva mirada me obligó a realizar un gran esfuerzo para modificar la manera de impartir la materia y redibujar el argumento tradicional. El carácter diacrónico se sostiene en el discurso del temario y a través de alguna de las prácticas obligatorias realizadas durante el curso (como la elaboración de un cuadro cronológico de artistas y obras). La mirada sobre la arquitectura se lleva a cabo en algunas prácticas de campo. Hay que tener en cuenta que los alumnos de la ETSA cuentan con dos asignatura específicas de Historia de la Arquitectura, donde ésta se estudia en profundidad. Para la elaboración de este nuevo proyecto docente, se solicitó una Beca PACE y tuve la oportunidad y la satisfacción de poder colaborar con una ex alumna que había cursado mis asignaturas, Berta Ferrer. Sus sugerencias, desde el otro lado del aula, su esfuerzo e implicación fueron de enorme ayuda y un acicate durante este proceso.

En realidad, nada ni nadie te prepara para lo que ha de repetirse...

Hace aproximadamente dos años hubimos de afrontar la contrarreforma del Grado. Era necesario, al menos así se nos trasladó, una revisitación de las materias y un replanteamiento dentro de la docencia. Pasamos de tener un Grado en Fundamentos de la Arquitectura, donde una de sus novedades -y las hubo de dimensiones colosales- fue la posibilidad de aportar optativas. La oportunidad de ofrecer al estudiante de Arquitectura una asignatura que, de alguna manera, no sólo se adaptara a nuestros estudiantes, sino también a las demandas profesionales, me inclinó a proponer una materia con un perfil diferente al habitual en la Escuela.

Nuestro alumnado se ha educado frente a una pantalla. Son los llamados nativos digitales; es una cualidad que les proporciona una cultura visual muy importante. Para ellos la imagen se ha convertido en un medio de expresión, información y comunicación. Como les digo en clase, a veces olvidan que incluso sus proyectos arquitectónicos no son literalmente arquitectura, sino en principio una imagen de ella. Por otra parte, la crisis en el sector y los cambios introducidos en el mercado laboral comienzan a solicitar un profesional que, entre otras cosas, domine las herramientas informáticas, sea capaz de hacer marketing a través de los medios que ofrece Internet y las redes sociales y que pueda convertir la imagen en un mecanismo de creación y/o en un medio de trabajo. Sobre estos mimbres nació Tramas y perfiles en la Cultura Visual. En ella se parte de la transversalidad planteada en la troncal de Historia del Arte, pero con una acento mayor en la interdisciplinariedad, pues se tratan asuntos relacionados con la pintura, la fotografía, el cine, la literatura o la arquitectura. De

(cc) EY-NC-ND 2016, Universitat Politècnica de València

Congreso In-Red (2016) 
este modo, temas como Érase una vez un cuadro o Pasa el pisito y verás, tratan la relación entre la literatura y la arquitectura con diversas disciplinas del campo de estudio.

Los estudiantes son futuros profesionales de la Arquitectura que deben moverse dentro del mundo en el que el diseño se ha convertido en una herramienta fundamental en la actualidad: para darse a conocer, para venderse u ofrecer al mercado un producto, para ser competitivos, para estar en la vanguardia, para crear algo nuevo que sea demandado por la sociedad. La Historia del Arte y Tramas y perfiles en la Cultura Visual son, en estos momentos, de las pocas asignaturas de la carrera de Arquitecto que pone énfasis en la imagen, más allá del objeto o el proyecto arquitectónico, para desarrollar este aspecto en la formación del estudiante. Ese fue el propósito inicial a la hora de plantear los nuevos programas y esa es la meta al final de cada curso. Aunque no todo se quedaba aquí.

\section{Objetivos}

Esta comunicación muestra el carácter innovador de dos nuevas asignaturas de Grado en los estudios de Arquitectura vinculadas a la Historia del Arte y a la Cultura Visual. Asimismo, este nuevo modo de abordar el programa permitió plantear una serie de prácticas en el aula que, además, de dar al alumno la posibilidad de ampliar sus conocimientos en la materia, le ayudan a desarrollar algunas de las competencias transversales implantadas en la UPV como la de la comunicación efectiva, tanto escrita como oral. Para la material de Historia del Arte se propuso la realización de blogs. Se trata de una herramienta de aprendizaje que, aunque ya utilizada desde hace algunos años, trajo consigo unos resultados óptimos y novedosos. Por otra parte, para la asignatura de Tramas y Perfiles en la Cultura Visual se diseñó una práctica específica denominada Cartografía personal. Es necesario, no obstante, incidir aquí en los objetivos de las propias asignaturas para comprender mejor las razones que motivaron su implantación.

El hecho de que ambas asignaturas trabajen sobre algo con lo que ellos están tan familiarizados, la imagen, podía hacer que consideraran las materias más atractivas y, por tanto, su aprendizaje fuera más eficaz. No se les habla de una historia, sino de diversas historias sobre el arte a través de los objetos y las imágenes que se han ido creando a lo largo de los siglos. Se les da, asimismo, la oportunidad de ejercitar su mirada para la contemplación, de dar contenido a su observación y de disfrutar llevándola a cabo. Sólo se conoce y respeta lo que realmente se ama. Es muy gratificante que los alumnos que han pasado por mis aulas me escriban para contarme que han visitado tal o cual museo y que han estado horas contemplando los cuadros y recordando lo estudiado en clase. Este, de hecho, éste se convirtió en el objetivo primordial de mis nuevos planteamientos o, si se quiere expresar de otro modo, mi nueva perspectiva sobre lo que quería que ellos se llevarán consigo: un aprendizaje continuo más allá de las aulas. Me di cuenta de que, aparte de períodos, artistas u obras, para mí era importante ofrecer una visión de lo artístico que les llevara a seguir adquiriendo nuevos conocimientos fuera del ámbito académico: "Los estudiantes universitarios necesitan seguir aprendiendo. Lo que hoy les enseñamos quizás mañana resulte caduco $y$, sin duda, será insuficiente. Los alumnos precisan continuar aprendiendo más allá de nuestras clases, una vez finalizados sus estudios formales" (Carlino, 2004, p. 8, en Rojas, Jiménez, 2012, p. 26).

(c)) BY-NC-ND 2016, Universitat Politècnica de València 
No obstante, había otros objetivos valiosos e incluso necesarios. Los estudiantes de Historia del Arte y Tramas debían:

1. Ejercitar la atenta observación de los objetos artísticos. Para miradas como las suyas asaltadas con cientos de imágenes a lo largo del día, es esencial enseñarles a descubrir los detalles, los últimos planos y las segundas lecturas.

2. Comprender las representaciones y su evolución a lo largo de la historia. Las obras no son sólo producto de los cambios dentro del ámbito artístico, son hijas de la cultura y la sociedad de su tiempo.

3. Superar la aproximación tradicional de la historia del arte basada en la cronología y los estilos o, lo que es todavía más importante, la división entre las Bellas Artes y las Artes Aplicadas. Les resulta muy difícil entender que no hay blancos y negros en la disciplina, ni son del todo válidas las clasificaciones a las que se somete a algunos artistas. Sencillamente no es posible.

4. Aprender a establecer relaciones entre el pasado y su presente. Siempre se sorprenden cuando descubren en otras épocas aspectos de su vida cotidiana.

5. Descubrir las estrechas relaciones que existen entre las diversas manifestaciones culturales. No son, ni han sido, departamentos estancos.

6. Cultivar la sensibilidad hacia el artefacto artístico sea cual sea su naturaleza.

7. Desarrollar su creatividad a través de las imágenes creadas por los artistas. Algo que es esencial para su futuro personal y profesional.

Es justo y necesario hablar de arte, perspectivas, miradas, imagen y cultura visual teniendo en cuenta la naturaleza de las dos asignaturas que imparto. Sin embargo, para mí, hay un elemento que no sólo da forma al aprendizaje, sino que también lo valida: la palabra, sea escrita u oral. Las circunstancias particulares de los grupos exigen todavía que parte de la evaluación se realice a través de controles donde los estudiantes exponen por escrito lo aprendido a lo largo del curso. La escritura y la lectura siguen siendo todavía mecanismos esenciales para la valoración del aprovechamiento y la formación académica del alumnos, sobre todo en asignatura de importante base teórica como las que imparto. De hecho, algunos de ellos tienen problemas con las materias, a pesar de carecer de complejidad, precisamente por no contar con las herramientas adecuadas para la expresión y la redacción.

Asimismo, en este momento se ven abocados a la realización de un TFG que les ha de exigir la lectura de una bibliografía y la redacción de un trabajo de iniciación a la investigación donde han de manejar contenidos, trasladarlos con una redacción clara y coherente e incluir citas y notas al pie que apoyen la argumentación. Como tutora de estos proyectos, he podido constatar las dificultades que muestran para la recopilación de material y para su elaboración: "quienes trabajamos como docentes universitarios sabemos por experiencia que muchos de nuestros estudiantes tienen serias dificultades para comprender y producir textos académicos; exponen sus ideas de forma aislada y esquemática; no desarrollan un plan previo ni un proceso sistemático de producción textual; desconocen los géneros y las convenciones de la escritura académica; tienen problemas de coherencia y de cohesión en el desarrollo de las ideas o transcriben literalmente los textos que leen, sin una apropiación y valoración crítica, sin hacerlas parte integral de su propio texto" (Peña Borrero 2008, p. 7). En ocasiones, todas esas dificultades 
manifestadas por Peña Borrero se traducen, desgraciadamente, en el temido y denostado corta-pega que deben evitar a toda costa. Tendemos a pensar que esto es algo que deberían haber adquirido anteriormente y que no tenemos por qué enseñarlo en la Universidad, pero hemos de pensar también que les estamos exigiendo una lectura académica y una escritura especializada que en la mayoría de los casos desconocen. Quizás por mi formación, procedo de la Universitat de València, soy consciente de la necesidad y valor de este género de trabajos, pero considero esencial también la implicación del profesorado en la formación de los estudiantes para abordarlo a lo largo de toda la carrera, en aquello que se ha dado en llamar alfabetización académica.

Por otra parte, a mis alumnos les he insistido en alguna ocasión que van encaminados al mercado laboral, van a ser profesionales destinados vender un producto a un cliente potencial. En los tiempos que corren, con una sensible crisis en el sector, éste puede ser un proyecto arquitectónico, unos renders o una página web. En muchas ocasiones estas propuestas van acompañadas de una memoria donde se desarrolla la justificación y probablemente seguidas de una presentación o una serie de entrevistas. En todo ello, la destreza para la escritura y la expresión oral son esenciales. Pueden marcar la diferencia a la hora de obtener un trabajo o el contrato para un proyecto. Saber escribir y hablar son cualidades básicas para aplicarlas al día a día en el mercado laboral.

Reconozco que las diferentes disciplinas tienen un lenguaje y un vocabulario propio que el estudiante debe adquirir a lo largo del curso, tanto en el campo del arte, como de la cultura visual y de la arquitectura. Como hemos señalado, son fundamentales tanto para obtener resultados óptimos en las diferentes asignaturas como para desarrollar, en el caso de que así lo decidan, un Trabajo Final del Grado de carácter más teórico. Sin embargo, también es cierto que el "énfasis que se le ha dado en la educación a escritura como dispositivo de comunicación y de evaluación ha relegado a un segundo plano la función mediadora que tiene la escritura como herramienta de pensamiento" (Peña Borrero 2008, p. 3). Es evidente que la docencia ha cambiado mucho en las aulas universitarias desde hace unos años, pero sigue vigente el modelo convencional, también válido, de clase teórica, donde el profesor expone los conocimientos que el estudiante ha de adquirir, y las clases prácticas de diferentes características (laboratorio, informática, de aula, de campo) en las que el estudiante aplica la teoría (Padilla Sabaté de Zerdán, Douglas de Sirgo, López, 2010, p. 3).

\section{Desarrollo de la innovación}

El replanteamiento de la asignatura de Historia del Arte y la introducción de la optativa sobre cultura visual me permitieron proponer prácticas donde los estudiantes pudieran desarrollar sus habilidades para la escritura y la exposición oral con unos objetivos diferentes. Con ellas no pretendo tanto que repasen lo estudiado en clase. Soy consciente que de este modo me alejo de un sistema docente centrado en el afianzamiento del conocimiento a través del trabajo activo en el aula y fuera de ella. Tal vez de modo inconsciente (¿intuitivo?) esté haciéndoles cultivar las competencias transversales. Valoro sobre todo que encuentren por sí mismos nuevas perspectivas de la materia, que se aventuren a exhibir sus propios gustos por otras manifestaciones artísticas, que exploren aspectos sobre ellos mismos y sus compañeros que desconocían, que disfruten de su

(c)) BY-NC-ND 2016, Universitat Politècnica de València 
libertad de expresarse y que sean, ante todo, imaginativos. Como afirma Ken Robinson: "La imaginación es la base de todo lo que es singular y característicamente humano. Es la base del lenguaje, de las artes, de las ciencias, de los sistemas filosóficos y de toda la inmensa complejidad de la cultura humana" (2012, pp. 90-91). Mi objetivo primordial es que se diviertan mientras se esfuerzan por pergeñar una idea, por hilvanar un argumento tanto por escrito como oralmente. De esa manera, descubrirán que, aunque la escritura también conlleva esfuerzo y sacrificio, se puede disfrutar tanto de ella tanto como del placer derivado de la comunicación con los demás.

En 2010 introduje en Historia del Arte la realización de blogs en el aula con unas caractererísticas particulares. Hasta el curso 2014-2015 mis estudiantes publicaron 99 blogs dedicados al arte y a la cultura en general. Algunos de ellos, como el titulado Si te he visto no me acuerdo (2011-2012), ha tenido hasta la fecha 24.277. La idea de que trabajaran con un portal de estas características como práctica surgió por un motivo esencial: el alumno que tenemos hoy en día. Él está habituado a vivir conectado permanentemente a Internet. Es un medio de comunicación esencial hoy en día y, sobre todo, de información. Para nuestros estudiantes el contacto con el mundo es a través de un teclado y de una pantalla de ordenador, de una tablet o de un móvil. Como nativos digitales, están habituados a manejar las nuevas tecnologías y las redes sociales con extraordinaria soltura porque, al fin y al cabo, han crecido con ellos y son el portal para experimentar y conectarse con un amplio colectivo... con todas sus ventajas y desventajas: "Las nuevas tecnologías se apoderan de nosotros y, sinceramente, somos la generación del high-tech. Aunque nadie quiera darse cuenta. Nosotros hemos nacido de la mano con Internet lo usamos a diario, creo que ya no podríamos vivir sin él."

He de reconocer que la elección de los blogs como herramienta educativa fue, en mi caso, producto de la intuición. La experimentación dentro del campo de la docencia la sitúan algunos autores en el año 2002 y se considera a las Universidades de Harvard y Stanford como las pioneras en el campo (Gewerc Barujel, 2005, p. 14). Conocía algunos blogs, no necesariamente especializados, y estuve consultando a estudiantes que habían pasado por mis aulas sobre la utilidad de estos portales de Internet. Necesitaba conocer la opinión de usuarios y egresados de Arquitectura que pudieran valorar desde otra mirada las ventajas de su implantación como práctica. Todos ellos se mostraron receptivos y me animaron a emprender lo que ha sido durante una años una auténtica aventura no exenta de esfuerzo y trabajo. González Sánchez y García Muiña realizan una clasificación de edublogs: personales (de docentes o expertos en educación), de instituciones, de aula y temáticos (2010, pp. 12-13). Con algunas matizaciones, los que propuse para los alumnos de estudiantes de Historia del Arte de la ETSA encajarían en el último apartado.

Los blogs debían tener un título y un diseño escogidos por ellos mismos, que serían valorados también en la calificación final de la práctica. Por este motivo, los estudiantes tuvieron que elegir formatos como los que entonces ofrecían Blogspot o Wordpress. Cada uno de sus miembros tendría un nick. Para ellos fue una auténtica sorpresa cuando, el primer día de clase, les pasé también el mío para que pudieran identificarme cuando contestara a sus entradas. Mi apodo nada tenía que ver con el arte y suscitó más de una

(cc) EY-NC-ND 2016, Universitat Politècnica de València

Congreso In-Red (2016) 
especulación durante el primer curso de implantación. No desvelé su origen hasta el final. Cuestiones tan sencilla como la de que el docente participe de la actividad con un nombre peculiar, establece cierta complicidad con el grupo y les anima a pensarse con cuidado cuál debía ser el suyo. Se pueden desvelar muchas cosas a través de algo tan sencillo como un nick. Les advertí de que leía y contestaba todas y cada una de sus entradas. Lo he cumplido a rajatabla todos los años. ¿Cómo podrían tomarse con interés una actividad como está si se dan cuenta de que el profesor no lee lo que escriben y no se toma la molestia de publicar un comentario por breve que sea?

Así pues, se organizaron una serie de blogs, montados por grupos de entre cuatro y seis alumnos, donde se introducirían las entradas obligatorias (diez cada estudiante) que incluían comentarios de exposiciones, fotografías realizadas por ellos (a las que debían dedicar unas líneas) y entradas en las que se estableciera una relación entre la publicidad o el diseño y el arte. Sin embargo, y esto creo que es lo que dio sus mejores frutos, les di libertad para introducir otro tipo de entradas relacionadas con la música (los videoclips se hicieron un hueco importante en los blogs), la literatura, la danza, el diseño, la arquitectura, el cine, la televisión, el cómic, el street art... Dentro de este grupo de no obligatorias realizaron algunas entradas estupendas. Constaté con ellas algo que sabía, que nuestros estudiantes sí tienen una cultura amplia (estoy cansada de escuchar todo lo contrario), les gusta la lectura (recuerdo magníficas entradas dedicadas a Oscar Wilde o a la poesía de Bukowski en el curso 2010-11), les apasiona la música, el cine o la danza. Y había un apartado especial de entradas en las que publicaban textos, vídeos o canciones en las que intentaban animarse unos a otros, consolidar su autoestima o plantear que una sociedad mejor es posible. Me di cuenta de lo mucho que necesitan el apoyo y el refuerzo. Algunos de ellos publicaron sus cuentos, sus cuadros o sus interpretaciones musicales. Son también artistas.

Eso me hizo pensar que sería una herramienta muy sugerente para ellos a la hora de elaborar sus trabajos y publicarlos. Asimismo, el hecho de que fuera público, aunque tenían la opción de poder limitarlo al grupo de clase, les hizo esforzarse doblemente a la hora de colgar un post. Eran conscientes de que se abrían de alguna manera al mundo y todos podían llegar hasta ellos. Por otra parte, "el texto electrónico, en cambio, le imprime a lo escrito una nueva textura, que se caracteriza por su fluidez y movilidad, y por propiciar una relación mucho más interactiva entre autor y lector. Ahora cualquier lector puede convertirse en lector-escritor, rompiendo así la brecha histórica que ha separado al autor y al lector" (Bolter, 1991, en Peña Borrero, 2008, p. 5). Ya no sólo se quedarían para la mirada del profesor, sino que verían la luz para otros lectores exigentes, críticos y/o competitivos: "La experiencia de los blogs fue algo diferente a cualquier ejercicio o práctica que haya hecho hasta ahora. Desde mi punto de vista, era muy interesante por el hecho de que se podía escribir sobre lo que se deseara, era algo así como una ventana abierta a cualquier expresión. Además permitía la opción de ver las opiniones de otros compañeros en sus blogs, siempre que éstos estuvieran de acuerdo".

Efectivamente, es inevitable que entre ellos se establezca cierta competitividad, pero es estimulante:

(c)) BY-NC-ND 2016, Universitat Politècnica de València

Congreso IN-RED (2016) 
1. Se nutren constantemente de información de manera productiva para publicar. A lo largo de los meses están pendientes de lo que conocen y también de todo lo que escuchan a su alrededor para volcarlo en el portal. Es un proceso de investigación y trabajo constante.

2. Es una manera atractiva de aprender sobre la amplia dimensión de la palabra Arte, tradicionalmente limitada a las "bellas disciplinas".

3. Se estableció una relación entre los miembros del grupo más estrechas, pues algunas de las entradas hablaban de cómo son y cómo se sienten dentro y fuera de las aulas.

4. Las contestaciones de su profesora revelaron que es humana (con aficiones e intereses como ellos). Se sintieron más cercanos a ella y, por eso mismo, más implicados con la asignatura.

5. Se dieron cuenta de que el aprendizaje no pasa únicamente por la clase magistral o los controles... Es algo que está en ellos mismos, en su propia e incesante curiosidad, y ique se puede disfrutar con ello!

6. La experiencia no se quedó dentro de los límites del curso: algunos blogs han continuado publicando entradas.

7. Su participación en los blogs estimuló la expresión pública de sus opiniones. Siempre les digo que su opinión SÍ me vale. “QQué es dar mi opinión?”, me preguntó una alumna una vez. Esa pregunta no debería volver a repetirse.

8. Las entradas pusieron de manifiesto la creatividad de los estudiantes de la ETSA.

9. Algunos de ellos hicieron de una materia, la de la Historia del Arte, que jamás habían dado en clase, una razón de ser para su formación como arquitectos. Y esto es, para mí como docente, una gran conquista.

La "contrarreforma" del Grado en Arquitectura, que en este momento se llama Fundamentos de la Arquitectura, me permitió impartir en el plan una nueva optativa en el último curso de la carrera. El fundamento de Tramas y Perfiles en la Cultura Visual y el programa me proporcionaron una cierta libertad a la hora de proponer las prácticas, sobre todo las que realizaba en el aula. La idea era que todas ellas resaltaran la importancia de la imagen con un valor por sí mismas, pero que también las destacaran como medios de expresión, como vehículos para transmitir un mensaje. Tenía claro que el grupo sería reducido, nada comparable a los 70 alumnos que he tenido este curso 2015-16 en uno de Historia del Arte, tendría mayor margen de maniobra a la hora de introducir aspectos que me serían imposibles en uno más numeroso. Decidí aprovechar la oportunidad para poder desarrollar algunas de las destrezas de los alumnos. Descarté la aquellas dedicadas a fortalecer los conocimientos adquiridos en la teoría de aula con la intención de fomentar otras competencias como la creatividad, la reflexión y la crítica, la escritura o, sobre todo, la expresión oral.

La pregunta esencial era: ¿cómo hacer hablar a un alumnado poco habituado a ello? No suelen participar en el aula, pregunta pocas veces y cuando lo hacen es porque necesitan aclarar alguna cuestión de lo explicado por el docente. Puedo contar con los dedos de la mano las ocasiones que a lo largo de este curso un estudiante de Grado ha levantado la mano para dar su opinión o compartir una idea. La respuesta, sin embargo, era muy sencilla: haciéndoles contar algo sobre ellos mismos. "Hablar es relacionarse, es intercambiar comunicación, compartir ideas o sentimientos, e intentar llegar a puntos de encuentro; es lograr a estos acuerdos o delimitar los desencuentros, es decidir y obrar en consecuencia. Por ello, comprendemos lo que significa cuando alguien nos plantea 
"tenemos que hablar"; interpretamos, sin duda, que nos enfrentamos a una situación en la que hay que tratar, compartir o debatir una cuestión o un tema para llegar a comprenderlo mejor conjuntamente e ir actuando según lo tratado y convenido. Y sabemos también que hablar implica, necesariamente, escuchar, mantener una actitud de escucha." (Ramírez Martínez, 2002, p. 59). Partiendo de esta idea, de que hablar es relacionarse, pero necesita también de un escuchante interesado, propuse en el aula una práctica que he llamado Cartografía personal. Este mapa individual consiste en cinco imágenes que el estudiante de Tramas debe escoger cinco imágenes. Cada una de ellas es una expresión de sí mismo, explica una parte de ellos: algún acontecimiento o experiencia vital o gustos personales (música, literatura, cine...), personajes que forman parte de su vida, mascotas, entre otros. Lo que sí es fundamental es que en ninguna de las fotografías salgan ellos mismos. Tienen alrededor de cinco minutos para hacer su exposición y luego se inicia una ronda de preguntas que, en ocasiones, termina en diálogo.

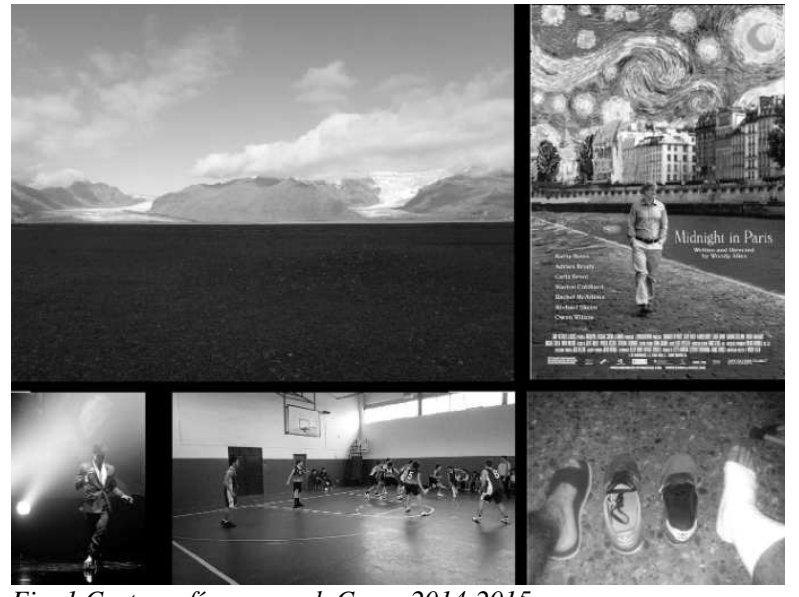

Fig. 1 Cartografía personal. Curso 2014-2015.

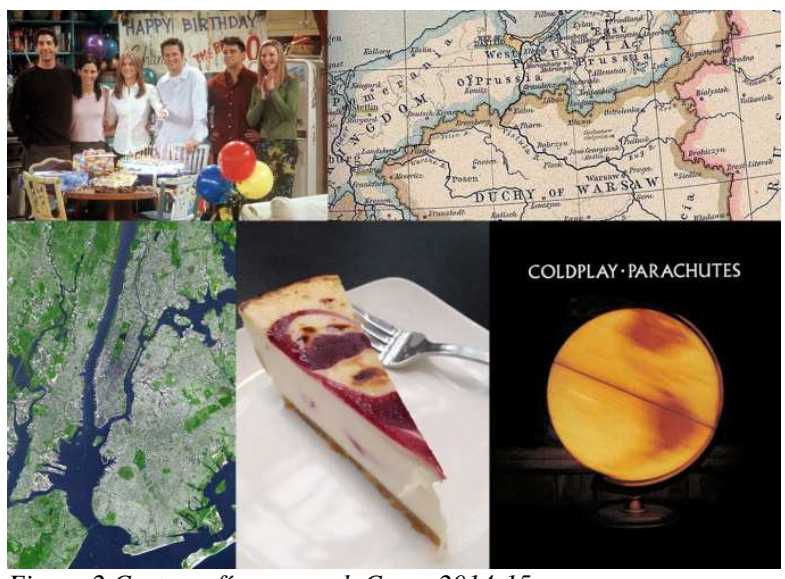

Figura 2 Cartografía personal. Curso 2014-15

A todos les cuesta muchísimo lanzarse a contar su cartografía personal. Por este motivo, el primer día de clase, cuando les explico el programa de la asignatura y las diferentes prácticas de aula, les muestro mi propio mapa individual. He seleccionado cinco fotografías que exhiben algunos de mis aspectos personales no académicos. Es fundamental cuando se quiere hacer este tipo de actividades en el aula, tan subjetivas, que el profesor se implique y haga gala de exhibicionismo. No tiene sentido hacerles exponerse a los demás, si quien 
propone el trabajo no está dispuesto a hacerlo también. Es algo similar al nick de los blogs. A veces, "bajar de la tarima" (muy excepcionalmente doy la clase sobre ella) y ponerse a su lado te permite conseguir mejores resultados, sin lugar a dudas. A pesar de sus temores iniciales a la hora de salir y contar su selección, para todos es enormemente gratificante, tanto para el que habla como para el que escucha a su compañero. Eso es una de las grandes virtudes de la práctica. Me llama mucho la atención que su tendencia natural es quedarse en la tarima para realizarla, tal vez porque necesitan estar cerca de la pantalla o tal vez para mantener algún tipo de distancia con respecto al oyente. Algunos de ellos escogen mostrar todas las imágenes en una sola diapositiva de PowerPoint, otros deciden ir pasando una a una. En uno u otro caso, se nota que no sólo han hecho un cuidadoso ejercicio de selección y sino que también establecen un hilo argumental para explicarse, nunca mejor dicho mejor. Este aspecto es muy destacable, pues una de las cualidades del buen hablante es, precisamente, planificar el discurso (Ramírez Martínez, 2002, p. 60). Es evidente que se toman en serio el ejercicio para mostrar lo mejor de ellos mismos o lo que mejor les define, pero también lo trabajan por respeto a su audiencia.

Cuando he explicado esta práctica a algún compañero me ha preguntado: pero tú ¿qué das? ¿arte o psicología? No dejan de sorprenderme esas preguntas. Ser docente es, entre otras cosas, ser un buen comunicador y comunica de verdad quien es capaz de conectar con su público. Para eso se necesita llevar un discurso preparado, demostrar que te apasiona lo que explicas, tener en cuenta a tu audiencia y observar sus reacciones para adaptarte a ellas. La cartografía les permite vivir esa experiencia de algún modo. Hablar ante una audiencia te puede poner muy nervioso, pero puede ser gratificante y divertido... como lo es ser un oyente interesado. Por lo tanto, la comunicación es una herramienta que nos permite conocer nuestro entorno y a las personas con las que trabajamos día a día. Un estudiante me dio las gracias por esta práctica. "Es la primera vez en esta Escuela que me permiten contar cosas sobre mí mismo". Otro añadió: "Parecía un pequeño ejercicio de presentación en clase, solo que no lo era. Era más. Conforme se iba exponiendo, se planteaban dos situaciones: la primera, el 'descubrimiento' de compañeros a los que no conocías; la segunda, sorprenderte de lo poco que conocías en realidad a tus compañeros de siempre". Me consta, pues después me lo cuentan, que desde el momento en que les explico de qué va, se ponen a pensar en qué quieren mostrar y, sobre todo, se pasan días escogiendo en las imágenes, que cambian una y otra vez. Hay quien me confesó que, viendo la presentación de sus compañeros, deseó tener la oportunidad de cambiar las suyas. Son demasiado jóvenes para saber que todos los seres humanos somos "muchos paquetes de cinco".

\section{Resultados}

Como resultados aporto las opiniones de algunos de mis estudiantes sobre ambas prácticas, en las que describen algunas de sus ventajas y virtudes. La de los blogs me dio la oportunidad de disfrutar de algo que considero básico en la labor de un docente: aprender de sus estudiantes. Todavía guardo anotaciones de aquellas entradas que me parecieron más interesantes. Al comienzo pensé que les costaría, que quizás se limitarían a los mínimos y no fue así. No lo ha sido en los cursos que esta práctica del blog ha estado en marcha. Todo lo contrario (el subrayado en sus comentarios es mío): "Está claro que teníamos unos mínimos que cumplir, aunque creo que nadie se limitó a éstos. Yo mismo creo que subí 6

(cc) EY-NC-ND 2016, Universitat Politècnica de València

Congreso In-Red (2016) 
fotos en vez de 3 (que eran las obligatorias). Además, esa pequeña vena competidora para que tu blog tenga más visitas que el de los demás, es algo extraordinario."

- "Desde el primer momento los alumnos se volcaron en la actividad, pues se nos daba gran libertad de expresión, y muchas personas incluso duplicaron el trabajo mínimo requerido. El ejercicio tenía como enunciado la puesta en práctica de lo aprendido en clase a través de temas de interés actual [...] mostrando el arte como algo vivo, un organismo que no pertenece únicamente al pasado, como en otros casos se nos hace ver."

- El arte está en la publicidad, en el cine, en la calle, iEN LAS REDES SOCIALES! Cuando comencé a escribir el blog para la asignatura descubrí que el arte es tan global como hoy en día lo es el mundo y sobre todo que está al alcance de cualquiera. Vamos, que quien no hace una visita virtual al MoMA o al Louvre, jes porque no quiere! Como decía, con este proyecto aprendí que el arte es algo integral, que el arquitecto no es solo arquitecto, es un fotógrafo, un escultor y un cineasta! Y viceversa, claro está.

El blog sobre todo me empujó a buscar, a explorar y a investigar. Repasando todas las entradas del blog desde el principio me doy cuenta de cuánto he aprendido desde entonces, incluso mucho después de haber dejado de escribirlo. Creo que ese es el verdadero motivo del blog, estimular a los alumnos a que se introduzcan dentro del infinito y siempre sorprendente mundo de la cultura y que cuando acaben la asignatura, no quede en algo anecdótico. El blog dejaremos de escribirlo, sí, pero ya estamos empapados de todas esas cosas que tanto nos han apasionado e inspirado, y si realmente ha sido así, ya no querremos salir."

Por su parte, la Cartografía Personal ha sido, sin lugar a dudas, una práctica de aula que me ha proporcionado grandes satisfacciones. Fue una experiencia humana de insospechadas dimensiones para todos aquellos que tuvimos la oportunidad de compartirla. Aquellas exposiciones trajeron consigo muchas más cosas de las que esperaba: sorpresas, sonrisas e incluso risas, emociones, lágrimas, sinceridad y ética. Salieron a la luz personas, temas muy interesantes e historias de gran interés cultural y humano. También pudimos presenciar la creatividad en la elección de los "autorretratos" y muy diferentes estilos comunicativos, algunos de ellos totalmente inesperados. Fue un excepcional ejemplo de lo que Ramírez Martínez denomina lenguaje integrado. No existe la expresión oral pura, pues está formada por numerosos factores y elementos que afectan tanto al hablante como al oyente, desde el espacio donde tiene lugar, el tono de voz, los gestos de los participantes e, incluso, la vestimenta (2002, p. 63). Aunque no seamos conscientes de todo ello, está ahí e influye en la comunicación.

Uno de los problemas que nos enfrentamos a veces en el aula es el de la competitividad entre los alumnos o entre los grupos de estudiantes. Algo que, de una manera cada vez más clara, Bolonia y la situación actual han ido acrecentando. Por otra parte, debido al número de estudiantes por aula, no terminan de conocerse entre ellos a pesar de estar juntos durante años. El mapa individual de Tramas provocó el efecto contrario. Les permitió conocerse más allá de las conversaciones superficiales de todos los días y generó una actitud de compañerismo que no había visto en mucho tiempo, por no decir jamás. Llegaron incluso a

(c)) BY-NC-ND 2016, Universitat Politècnica de València

Congreso IN-RED (2016) 
crear un grupo de WhatsApp que abarcaba a toda la clase. Eso hizo mucho más fluido el transcurso del curso. La realización de otras prácticas de índole similar, quizás incluso más complicadas, obtuvieron resultados óptimos. Se descubrieron a sí mismos y aprovecharon las oportunidades que la materia y el trabajo les proporcionaba. No hubo ningún suspenso y las calificaciones fueron muy altas. Complicidad total en el grupo + Implicación completa con la asignatura = Máximo rendimiento.

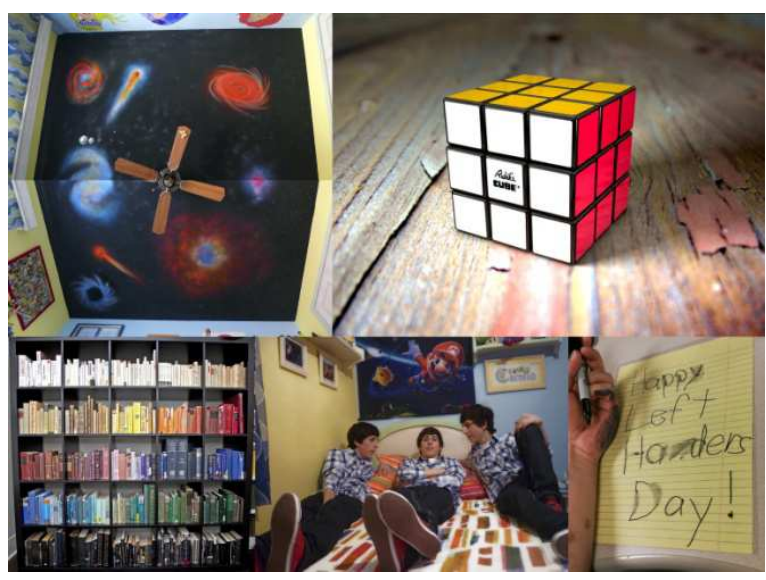

Fig. 3 Cartografía personal. Curso 2014-2015

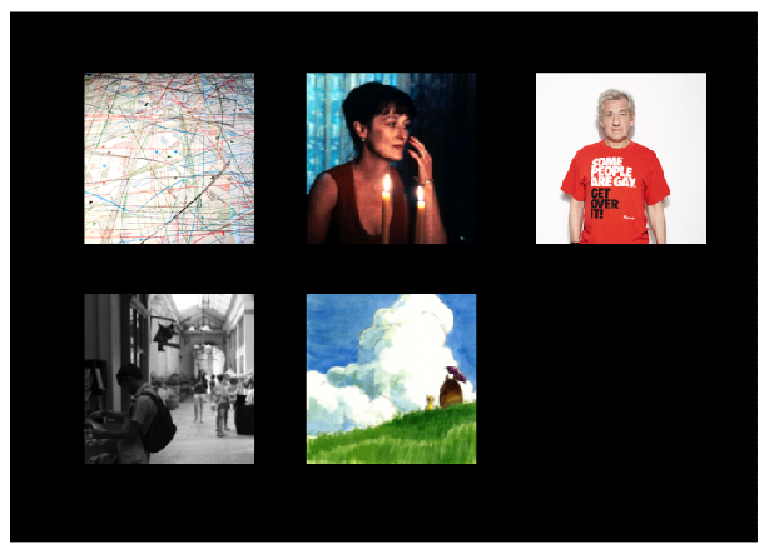

Fig. 4 Cartografía personal. Curso 2014-2015

"La práctica de la Cartografía Personal fue para mí la más estimulante que hicimos en clase. Era probablemente la más sencilla de todas, y sin embargo recuerdo comenzar a prepararla con dos semanas de antelación. Hablar de uno mismo supone una gran responsabilidad social. Lo que uno oculta y revela de sí mismo ante los demás obliga a reflexionar sobre cómo somos y cómo queremos que nos vean. Es un verdadero autorretrato. Deseaba presentar mi Cartografía Personal lo mejor que pudiera, y por eso me lo escribí todo, aunque no se nos pedía. Primero quise mostrar las cinco imágenes al mismo tiempo, para suscitar curiosidad en mis compañeros. Al observarlas a la vez, sin explicación alguna y sin conexión entre ellas, se generaba una sensación de desconcierto. Poco a poco, el discurso iba hilando esa constelación de imágenes y transformaba lo 
aparentemente aleatorio en un cuerpo sólido y con sentido, una representación de la personalidad."

"La cartografía personal fue el primer ejercicio que realizamos para la asignatura "Tramas y perfiles de la cultura visual”, en la que uno de los temas tratados era el valor de la imagen para expresar una idea o para significar mucho más de lo que a simple vista parece. En este sentido, el ejercicio era muy coherente porque nos obligaba a expresar mediante imágenes cinco ideas que nos definiesen (gustos, intereses, experiencias...) sin recurrir a explicaciones escritas. Por lo tanto, teníamos que seleccionar las imágenes adecuadas y pensar muy bien cómo organizarlas y qué orden seguir para hacernos entender. El ejercicio era una oportunidad para conocerse y reflexionar (qué cinco ideas me "resumen" o qué quiero que se sepa de mí o qué imagen quiero dar al resto de compañeros...), lo que es un punto muy positivo. Sin embargo, lo mejor del ejercicio, en mi opinión, fue que nos permitió encontrar en clase a personas con nuestros mismos intereses, gustos similares o historias parecidas. El ejercicio sacó a la luz temas de conversación, ideas comunes, e hizo que quisiéramos conocer a personas con las que, de otro modo (por timidez o por prejuicios), no nos habríamos relacionado tanto. Generó, en definitiva, un ambiente más relajado y de confianza en el que todos nos conocíamos un poco mejor"

\section{Conclusiones}

Jamás había trasladado por escrito mis experiencias dentro del campo de la docencia. En ese sentido, este texto ha sido para mí una novedad. Mis propuestas para el aula no son muy distintas a las que han llevado a cabo otros compañeros míos, pero es posible que los resultados sí sean algo distintos y cuantificables de otro modo. He de reconocer que buena parte de las prácticas que he realizado y realizo en clase no están diseñadas para reforzar o consolidar los conocimientos impartidos en la teoría. La intención es romper los límites habituales que ofrece un programa (en más de una ocasión me he preguntado qué pasaría si no existiera), con la idea de que encuentren nuevos matices en las asignatura que estudian conmigo y de suscitar su interés más allá del curso. El hecho de que algunos de los blogs desarrollados en Historia del Arte siguieran activos después de la asignatura es un buen ejemplo de esto último. Siempre he respetado a aquellos compañeros que promueven prácticas en las que se ofrece a los estudiantes un camino pautado. No negaré que en determinadas disciplinas o debido a determinados objetivos es necesario hacerlo. Sin embargo, el rendimiento y los resultados que he obtenido dando cierta libertad en los temas de los trabajos, a partir de una premisa general común, o de presentación han sido, en general, muy aceptables, en algunos casos incluso excepcionales. Es cierto que a algunos les cuesta enfrentarse a horizontes tan amplios. "Es que yo no tengo imaginación", me dijeron una vez. A lo que yo contesté que eso era un problema para un futuro arquitecto... y para un ingeniero, un matemático o un director de empresa. Mentiría si dijera que el método es infalible y que siempre funciona. No es así, pero en su imperfección, me concede grandes satisfacciones. Siempre he entendido la docencia como un recorrido de ida y vuelta. Estas prácticas lo han demostrado. Ellos aprenden y yo aprendo de ellos desde el respeto, el entusiasmo y la complicidad.

\section{Referencias}

(c) BY-NC-ND 2016, Universitat Politècnica de València

Congreso IN-RED (2016) 
ARNOUX, E., BORSINGER, A., CARLINO, P., DI STEFANO, M., PEREIRA C. y SILVESTRI, A. (2004). La intervención pedagógica en el proceso de escritura de tesis de posgrado. Revista de la Maestría en Salud Pública, 2 (3) 1-16.

BOLTER, J. D. (1991), Writing space. The computer, the hipertexto, and the history of writing. Hillsdale, N. J. Lawrence Erlbaum.

CARLINO, P. (2002), “¿Quién debe ocuparse de enseñar a leer y escribir en la Universidad? Tutorías, simulacros de exámenes y síntesis de clases de humanidades”. Lectura y vida, sin paginar.

http://www.unisabana.edu.co/fileadmin/Documentos/Pedagogia Infantil/QUIEN DEBE OCUPARS E DE ENSE æAR A LEER Y ESCRIBIR.pdf [Consulta: 15 de marzo de 2016]

CARLINO, P. (2004), "Escribir en la universidad responsabilidad compartida entre alumnos, docentes e instituciones". Textos en Contexto. Leer y escribir en la Universidad. N. 6, Buenos Aires: Asociación Internacional de Lectura, pp. 5-21.

GEWERC BARUJEL, A. (2005). "El uso de weblogs en la docencia universitaria". Revista Latinoamericana de Tecnología Educativa, 4 (1), 9-23. [http://www.unex.es/didactica/ RELATEC/sumario_4_1.htm] [Consulta: 1 de abril de 2016]

GONZÁLEZ SÁNCHEZ, R.; GARCÍA MUIÑA, F. E. (2009), "El blog en la docencia universitaria, ¿una herramienta útil para la convergencia europea?”. Relada. Revista Electrónica ADA. 3 (2). Madrid, pp. 135-144.

GONZÁLEZ SÁNCHEZ, R.; GARCÍA MUIÑA, F. E. (2010), "Propuesta de un modelo de medición del desarrollo de los blogs educativos. Una aplicación empírica al sistema educativo español". Revista de Formación e Innovación Educativa Universitaria. Vol. 3, № 1, pp. 8-20.

MARZAL GARCÍA-QUISMONDO, M. A.; BUTERA FAJARDO, M. J. (2007), "Los blogs en el nuevo modelo educativo universitario: posibilidades e iniciativas". Textos Universitaris de Biblioteconomia i documentación. N. 19. Facultat de Biblioteconomia i documentación. Universitat de Barcelona, s. p.

PADIlla SABATÉ DE ZERDÁN, C.; DOUGLAS DE SIRGO, S.; LÓPEZ, E. A. (2010), "Competencias argumentativas en la alfabetización académica". @ tic. Revista d'innovació educativa. N. 4. Universitat de València, pp. 1-11.

http://media.utp.edu.co/referencias-

bibliograficas/uploads/referencias/articulo/padillayotros2010compentenciasargumentativasenpdfdfrlS-articulo.pdf [Consulta: 18 de marzo de 2016]

PEÑA BORRERO, L. B. (2008), "La competencia oral y escrita en la educación superior". Comité Consultivo para la Definición de Estándares y Evaluación de Competencias Básicas de Educación Superior. Ministerio de Educación Nacional, pp. 1-10.

http://www.mineducacion.gov.co/1621/articles-189357_archivo_pdf_comunicacion.pdf [Consulta: 24 de marzo de 2016]

RAMÍREZ MARTÍNEZ, J. (2002), “La expresión oral”. Contextos educativos. N. 5. Universidad de la Rioja, pp. 57-72.

ROBINSON, K. (2012), El Elemento. Barcelona: DeBolsillo Clave.

ROJAS NORIEGA, G.; JIMÉNEZ MAHECHA, H (2012), "La educación superior desde la lectura y la escritura”. Revista Amazonia Investiga. Florencia (Colombia): Universidad de la Amazonia. Julio-Diciembre, pp. 19-35.

(cc)) EY-NC-ND 2016, Universitat Politècnica de València

Congreso In-Red (2016) 